\title{
Dynamics and Potentiality of Postgraduate Students Regarding Lifelong Learning: A Greek case
}

\author{
Sofia Boutsiouki \\ Department of International and European Studies, University of Macedonia \\ 156 Egnatia Street, P.O. Box 1591, 54006 Thessaloniki, Greece \\ Tel: 30-23-1067-3451Ｅ-mail: sofiab@uom.gr
}

\begin{abstract}
The purpose of this article is to contribute to a gradually expanding discussion on the role of lifelong learning in the personal and professional lives of individuals, as well as on the socioeconomic trends and practices in the global context. It presents the results of a survey carried out with a structured questionnaire on postgraduate students in social and economic sciences in a Greek university, in order to explore their views, perceptions and attitudes regarding lifelong learning; it also explores the way in which these factors guide their ideological commitment of lifelong learners, as well as their corresponding dynamics and potentiality. The definition of these determinants would significantly enable the effective implementation of lifelong learning by contributing to a wider range of interventions, varying from planning activities to eventually influencing the socioeconomic environment and transforming relevant national and supranational strategies.
\end{abstract}

Keywords: Lifelong learning, Adult learning, Postgraduate studies, Professional development, Social qualities

\section{Introduction}

The purpose of this article is to contribute to a gradually expanding discussion on the role of lifelong learning in the lives of individuals. It aims at exploring the perceptions and the attitudes of a group of Greek postgraduate students towards lifelong learning both as a dynamic (justification of their choice to actually attend lifelong learning) and as a potential process (evaluation of its socioeconomic role and estimation of their ability for future participation overcoming any obstacles).

At first, a brief overview of the context of lifelong learning rhetoric is presented, followed by a description of the research design, the basic research questions and the methodology. Finally, the findings, presented in both a descriptive and a tabular form, are thoroughly examined in order to draw useful conclusions. These conclusions are indicated at the end of the paper.

\section{Modern rhetoric on lifelong learning}

In post-modernity, it has become undeniable that knowledge is one of the most important sources of future advantages for individuals, employers and national economies. The instability of views and the complexity of conditions demonstrated the need for reorganization and enrichment of the knowledge base and of the intellectual capital of individuals; thus, their normal incorporation and maintenance in the social reality would become attainable throughout one's lifetime. For this reason a very strong trend has developed towards redefining educational goals and reforming the educational systems in all levels and in both formal and non-formal settings. The "pressure" towards the implementation of the appropriate changes stems from (active or potential) learners, family environments, employers and all kinds of stakeholders. The general aim is to apply innovative strategies and effective practices, which respond flexibly to the new economic, social, political or cultural conditions, and to satisfy new learning needs that arise. Beyond that, the concept and the meaning of the term learning gradually replace the term education in many applications, conveying an inclusive essence and combining — with no exclusions - knowledge, employment and spare time activities in a creative and interactive way of living (Jarvis, 1998; Green, Wolf and Leney, 1999; Edwards and Usher, 2001).

The content of lifelong learning and its influence on human capital development have been discussed for many years now and have enriched the relevant rhetoric with intellectual reasoning. This discussion has led to a thorough analysis of certain aspects of the issue and has contributed to the formation of the lifelong learning concept as a totality (Aspin and Chapman, 2007). The definition of the term lifelong learning accepted within the framework of the present article is the one adopted by the European Union and used in the official documents:

"Lifelong learning includes every learning activity undertaken throughout life, with the aim of improving knowledge, skills and competences within a personal, civic, social and/or employment-related perspective.” (Tissot, 2004, p. 102) 
The necessity to organize and to develop human capital which a person may and at the same time must use and renew throughout his/her lifetime, has grown and has led to the wider access and the increased lifelong participation in all forms of human capital development. Therefore, the attention of educational organizations and policy makers has been directed towards the development of individual abilities and skills and the production of larger numbers of more flexible, adaptable and efficient graduates, who are expected to increase their prospects and subsequenltly their employability (Edwards, 1993; Jacquemin and Pench, 1997; Harvey, 2000; Brown, 2003). At the same time lifelong learning is considered to influence the social, economic and ideological aspects of human life and to define human well-being. The need to establish a new lifelong learning model, which is operational and interactive with social and economic activity as a whole, refers not only to policy-makers and employers, but also to individuals themselves, whose responsibility to make the proper strategic planning and to apply the best choices increases (Brown and Lauder, 1992; European Commission, 1993; European Council, 1997; Hake, 1998).

As time passes, the deeper purposes of lifelong learning take on new forms. For a long time the notion of lifelong learning had been confined to employment/profession oriented aims and competitiveness purposes to the exclusion of a more general definition; thus, it led the learning society to specific policies and measures (Tight, 1998; Coffield, 1999, p. 1-12; Harman and Brelade, 2000, p. 29-30, 62-67, 69-71). For many, lifelong learning has been deemed as a means to enlighten people and to lead to social change. Today, lifelong learning becomes less "collectivist", leads participants to a self-development focus and can definitely be described as a high-individualized form of learning process (Field, 2006, p. 55). These conditions result in redefining the knowledge society and lifelong learning as pathways to development on the level of both politics/ideology and people's everyday life. It can be argued that nowadays lifelong learning has developed a new, broader concept, which not only refers to ideological and political aspects of modern learning- for some knowledge - society, but is also expected to affect the actual life and well-being of individuals. This influence is no longer limited to younger ages, but has realigned its width, depth and duration in terms of rhetoric and practice (Hughes and Tight, 1995; European Commission, 1995; Griffin, 1998; Wain, 2000).

In our era, socioeconomic transformations have become a more complex, but more substantial process. For this reason the learning society is no longer guided solely by economic factors, but by changes of individual values, social interdependent relations and new ways of life (Field, 2006, p. 77). Learning already relates to both the strictly school environment, in a narrow sense, and the broader socioeconomic environment, in a wider sense. It constitutes a cultural capital, which defines the views, beliefs and perceptions of people about themselves, about others and about the environment where they live and function. This process is continuous and leads to the redefinition, reassessment and evolution of ourselves (Bourdieu, 1986). Lifelong learning is also considered a special requirement for both survival in a competitive, unstable and unfavorable environment and personal success (Checchi, 2006). For this reason, it must be carefully approached as an element of "life-politics" towards human self-actualization and studied within a wider context of profound individual and socioeconomic transformations (Giddens, 1991, p. 214).

The interest for the development of lifelong learning and the accomplishment of the above-mentioned tasks is strongly related to the understanding of adult motivation to undertake lifelong learning, so that the proper decisions are made. This motivation is rather complex and can be influenced by external factors and subjective individual perceptions and expectancies for the environment and oneself (Rubenson, 2000). Patricia Cross' Chain-of-Response (COR) Model depicts in a descriptive way that the decision of adults to become learners results from the interrelation of a number of variables, which form a chain of responses (Cross, 1981, p. 124-131) based on the individuals' evaluation of their position in the socioeconomic framework (Note 1).

The same discussion is developed on a policy level, too. The incorporation of lifelong learning into the socioeconomic systems and the derivative policies of at least most post-industrial states can be easily observed primarily by considering the alterations in the relevant strategic planning of important supranational organizations (Hantrais, 2000, p. 5; European Council, 2002; OECD, 2007; UNESCO, 2008), since learning stopped being a strictly national affair, mainly due to globalization; then, this same pattern was enforced by nation states. Lifelong learning has acquired an important role in the strategic planning and policy implementation of modern nation states and acts as a crucial competitive advantage, creating a base for them to develop more welfare, tolerance and democratic values and avoid social exclusion (Commission of the European Union, 2001, p. 3-7; OECD, 2001; European Council, 2002, § 10; Kleinman, 2002). Moreover, it has the ability to exercise a significant influence on a personal level, helping individuals in their struggle for personal fulfillment, active citizenship, social inclusion and employability/adaptability (European Commission, 2001, p. 9; 2002).

\section{Previous Research Literature}

The promotion of the lifelong learning strategy is based on the perception that it is able to exercise a major influence on every aspect of human life and empirical studies seem to support this contention.

Through a survey conducted in Finland, Jauhianen (2007) analyzed the attitudes and experiences that ageing people attach to education and learning and examined aspects of lifelong learning. He demonstrated that individuals with a 
higher educational background showed a more positive and optimistic attitude towards learning than others; but, when they were asked to evaluate it in the case of more concrete issues, such as solving social and employment problems, this highly positive attitude diminished and the effectiveness of learning in human lives was implicitly doubted.

Mihail and Elefterie (2006) conducted a survey in order to investigate graduates' perceptions on a Greek MBA program as well as its impact on their careers. The respondents revealed their belief that they benefited from continuing their learning activity; the specific program helped them pursue managerial careers and increase their employability, because they were able to negotiate successfully for new and challenging job positions.

Field (2005) explored the question of the relationship between social capital and lifelong learning through the analysis of people's responses to the 2001 Northern Ireland Life and Times Survey. The findings suggest a clear association between positive attitudes towards lifelong learning and positive attitudes towards a range of different forms of civic engagement; there is also a mutually beneficial association between social capital and lifelong learning with interesting implications for both individuals and policy-makers, but the extent to which one causes the other remains undetermined.

The General Directorate for Education and Culture of the European Union commissioned a survey (Cedefop, 2003), in order to define the learning preferences of Europeans. The findings show that they recognize the benefits of lifelong learning for personal, social and economic purposes; it helps people both to cope with change and labor market demands and to have an independent and satisfactory life. They deem it suitable for all ages and more profitable in non-formal contexts; nevertheless, they prefer formal settings for the improvement of their professional skills, obviously emphasizing on official certification. The survey also confirms that those with higher educational and occupational levels are more likely to participate in various forms of lifelong learning. Although individuals underline that money and lack of time due to job and family commitments are important obstacles, they are willing to make a financial contribution, if they judge the benefit to be an exclusively personal one; on the contrary, they do not see work-related learning as solely their responsibility.

Jenkins et al. (2003) found that acquiring qualifications within the school system increases the likelihood of undertaking lifelong learning, but undertaking actual lifelong learning programs increases the probability for someone to attend more lifelong learning in the future. Lifelong learning does not seem to have an important effect on earnings, but there is strong evidence that it is associated with a higher probability to enable or preserve someone's presence in the labor market. At the same time, the authors acknowledged that they did not investigate the individuals' motivation to participate in lifelong learning, yet they believe that we should expect different outcomes and benefits from lifelong learning programs with differently oriented aims.

Illeris (2003) analyzed data from the Danish Adult Education Research Project (1997-2000), which referred to poorly educated or unemployed adults. He found that their majority entered learning programs because they were forced to do so and not because of their interest to learn; he concluded that adults have little inclination to learn something they do not perceive as meaningful for their goals and set themselves the limits of their learning, if they are allowed. This finding shows that lifelong learning should focus more on adult guidance and motivation.

A comparative analysis (Schuetze and Slowey, 2002) gave emphasis to the institutional factors, which affected the participation of lifelong learners in higher education in ten developed countries (Austria, Australia, Canada, Germany, Ireland, Japan, New Zealand, Sweden, United Kingdom and United States). Although the researchers acknowledge that national differences of culture, traditions and structures differentiate the degree of integration of individuals in the lifelong learning system, they identified common factors that determine their motivation and participation. The majority tended to enroll in non-university institutions and vocationally oriented programs, while flexible or open access to the programs, usually based on specific personal characteristics and previous achievements, seemed to exercise a positive influence. Practices removing institutional barriers that associated to the mode of study, such as information and communication technologies or flexible course programs, increased students' potential. The cost of the programs and the lack of financial support also influenced motivation negatively, while the availability of lifelong learning programs not only in higher education institutions, but also to other education providers, broadened opportunities and facilitated participation.

The Organization for Economic Co-operation and Development (2001) in search for the crucial factors of economic competitiveness discovered a relation between human and social capital; this may act as an important parameter of a socially sustainable strategy for competitiveness and development.

Kember (2000) studied evidence from over 90 action research projects on Asian university students exploring among others their motivation to learning experiences. He concluded that they were incited by extrinsic motivation, mainly by the prospect of a successful career, which is commonly accompanied by an interest in the course content; nevertheless, intrinsic motivation, abeit expressed indirectly, existed, too. These students also showed high levels of achievement motivation, which had a less individual and a more collective character, due to the cultural differences between Asian and Western civilization. 
Tamkin and Hillage (1997) explored the issue of the commitment of individuals to learning throughout lifetime. There is general belief that learning processes produce positive benefits, especially for participants; for this reason, the individuals are willing to invest in lifelong learning aimed at their personal development, although there is no certainty that this investment will actually have a positive effect. On the contrary, benefits for employers are not clearly defined yet, but still they believe that learning development is beneficial.

\section{The survey}

\subsection{The postgraduate programs in general}

In order to examine the research questions mentioned below, a survey was designed and conducted during the period April-May 2009 on students of six postgraduate programs in Social and Economic Sciences at the University of Macedonia, located in Thessaloniki, Greece. These students were accepted into these postgraduate programs through a procedure, which consists of written examinations and an interview. The broad conception of the individuals' need for more formal qualifications and essential skills to satisfy labor market demands and the recognition, which the studies at the University of Macedonia have established among Greek educational institutions, have made these four semester programs very attractive and highly competitive.

\subsection{Key Research Questions}

The fact that postgraduate students are themselves a part of the lifelong learning process corroborates the significance of the exploration of their views and their experiences in relation to lifelong learning; it reveals important aspects of the motivation and the reasoning, which formulate the relationship between these individuals and lifelong learning activities. The survey was structured under the general hypothesis that well-educated individuals, such as postgraduate students, develop necessity, eagerness, concrete consciousness and devotion to the exploitation of learning opportunities. Moreover, we deemed it particularly important to explore how lifelong learning shapes attitudes and values related not only to social and economic aspects of life, but also to self-determination and formation of human self-identity.

The basic questions of our research are:

i. How do these postgraduate students evaluate the role of lifelong learning in the personal, social and economic life of individuals and how does this affect their learning choices?

ii. Which reasons would lead them to attend a lifelong learning program with reference to their previous experiences?

iii. How do personal characteristics, such as gender, age, social origin and professional status, influence their assessment?

iv. What are the obstacles involved in their participation — therefore, potentiality—in lifelong learning?

\subsection{Questionnaire of the survey}

The structured questionnaire that was used as a research tool consisted of two parts. In the first one the participants provided their personal demographic characteristics. In the second one, there are questions with given statements that aim at justifying the subjects' choice to attend lifelong learning -postgraduate studies included- ("dynamics") and at exploring their perceptions for the socioeconomic role of lifelong learning related to their ability to pursue it overcoming any participation obstacles ("potentiality"). There were firstly questions specifically referring to the respondents' previous lifelong learning experiences; their answers were valuated through a Likert scale ranging from $1=$ no significance to $5=$ very high significance; secondly, the perceptions and attitudes towards lifelong learning were explored through the expression of their agreement to statements referring to its role; these were put in random order to avoid any prejudice and grouping of the answers and the levels of preference were set again by the Likert scale varying from $1=$ totally agree to $5=$ totally disagree.

\subsection{Statistical Analysis Methodology}

The description of the qualitative variables was done with frequency tables and bargraphs, while the chi-square test was used to assess the homogeneity of the distributions that arose. The correlation of the qualitative variables was done with the use of connection tables (crosstabulation); chi-square test was used to check the independence between the pairs of the variables under examination. The statistical adjusted residual was used in order to locate the statistically significant results of the test (values that are greater than 2 indicate a statistically significant relation among the corresponding categories), while the test validity was checked with the multitude of the cells with the expected frequency smaller than $5(<20 \%)$. For the formation of the lifelong learning approach components the model of Factor Analysis was applied with the method of Principal Component Analysis (extraction method) and the Varimax with Kaizer Normalization (rotation method). The checking for the propriety of the method and the correlation of the variables under consideration was done with the Kaiser-Meyer-Olkin Measure of Sampling Adequacy (KMO Test $=0.614>0.6)$ and Bartlett's Test of Sphericity criteria (it was statistically significant $\mathrm{p}<0.001$ ). The credibility of the components was tested with the calculation of the Cronbach's Alpha coefficient. The results showed five groups of statements, which were added in 
order to give a general estimation of the attitude of the respondents towards each one of them. The correlation among the five components was done with the use of the Pearson correlation coefficient. Moreover, Friedman testing was used in the groups of variables of every component aiming at checking the hypothesis that all statements get the same score in average (Mean Rank). The whole statistical analysis was realized with the use of SPSS 15.0 and the statistical significance level was set for $P<0.05$. (Tabachnick and Fidell, 2001; Green, Salkind and Akey, 1997).

\subsection{Sample of the survey}

The survey was conducted with a structured questionnaire, which was distributed to 108 postgraduate students personally by the author during course hours; the questionnaires were gathered a few days later, so that there would be enough time for a careful and credible completion.

The $41.7 \%$ of the participants were men and the other $58.3 \%$ were women, originating from various undergraduate studies; almost half of them were over 30 years of age and had graduated at least six years earlier, but neither this fact nor family status were an obstacle in their choice to continue their studies. Their participation by postgraduate program is shown in Table 1.

The parents' educational and professional status is rather high for a great majority of the participants; the father and the mother of one third of the sample (30.8\% and $28 \%$ respectively) are tertiary education graduates, while an additional $6.5 \%$ and $3.7 \%$ respectively hold a postgraduate or doctoral degree. This finding confirms that individuals originating from a well-educated family of a higher professional status tend to continue their studies at a higher level, with much more ease and determination; of course, individuals whose parents had a lower educational and professional status seem subconsciously motivated to continue studying by their parents' aspirations for higher attainments, in order to validate their social and employment status and become "upwardly mobile" (Floud, Halsey and Martin, 1957; Parsons, 1959; Halsey et al, 1961; Bourdieu, 1971; Cross, 1981, p. 67; Checchi, 2006). Nevertheless, a difference in their dynamics and in their projected potentiality is implicit in the unequal ability of every family environment to offer them effective guidance and support to succeed in their tasks.

\section{Findings and Discussion}

\subsection{Professional status of the sample}

The specific group of postgraduate students was considered suitable for the exploration of adults' dynamics and potentiality regarding lifelong learning because their attendance in a postgradute program of studies was actually a form of lifelong learning participation and served the same ideology and policy aims (European Commission, 1993; 2002; European Council, 1997, p. 6). Moreover, the overwhelming majority of the sample was employed at the time of the survey (Table 2.1) and more than half of them had been working for more than five years; thus, they were expected to have already formulated a more accurate opinion and a specific attitude towards lifelong learning. Finally, their successful completion of undergraduate studies and their employment status suggested a satisfactory sense of self-esteem, which affects positively their motivation for lifelong learning achievement (Cross, 1981, p. 125, COR Model, point A).

The employed respondents were mainly salaried employees in the public and private services sector, which offers job security and stability, while very few (7.1\%) were entrepreneurs (Table 2.2); this fact can be attributed to the limited development of entrepreneurship in Greece, especially in SMEs; although data is limited, it can be argued that Greek entrepreneurs still lack the mentality of participating in lifelong learning activities themselves (postgraduate studies being one of them) in order to broaden their knowledge and skills and reinforce their professional efficiency. The students show a major dynamics expressing their expectancy on meeting important goals; but the possibility of lifelong learning participation to be financed either by EU and Greek state resources or by their employers seems to actually affect their potentiality, therefore their final decisions (Cross, 1981, p. 126, COR Model, points C and E). Although a strong dynamic can be observed for both genders-clearly ascending educational and professional mobility compared to the parents - in general, fewer women than men exercise independent professions or hold job positions with greater responsibility (Table 2.3).

\subsection{Information sources on lifelong learning}

Information is considered to have a significant importance, because it provides the link between already motivated learners to the appropriate lifelong learning opportunities (Cross, 1981, p. 127, COR Model, point F). The Internet and to some extent other forms of mass media are the main information sources of the respondents for lifelong learning programs; informal social networks seem to play an important role, too, mostly for women (Table 3).

\subsection{Participation in the postgraduate program and in lifelong learning activities}

Almost one out of three respondents of both genders had already participated in at least one lifelong learning program. These referred mainly to economics, management and ICT and were organized either by universities or by—private or 
public - vocational training centers; tuition fees were paid mostly by employers or, in several cases, were subsidized by EU resources, while very few were paid by the participants.

The motivation and the reasoning for their participation in both the postgraduate program and future lifelong learning at their own expense were quite similar and reveal their dynamics and their potentiality. Table 4 presents both groups of reasoning in order to facilitate the comparison between them.

Personal interest clearly exercises the greatest influence, but the mentality is mainly orientated towards professional parameters and on their influence on the individuals' transition, the presence and the probable development in the labor market. This profession-oriented framework includes elements indirectly referring to professional position or financial advancement, special knowledge and skills or broader acknowledgement in the labor market. It can be argued that their primary motivation derives from their determination to secure employability by acquiring and deploying knowledge, skills and attitudes and presenting them to their current or future employers or to the context in which they work (Cross, 1981, p. 124-127; Hillage and Pollard, 1998; Kember, 2000). However, there is an interesting argumentation referring to the "voluntary" or "mandatory" character of lifelong learning participation; although employers do not directly require constant knowledge and skills updating, the intense competition in the labor market exercises a certain coercion linking adult learning to professional advancement (Cross, 1981, p. 241-242).

Younger ages believe more strongly in the value of lifelong learning and consider it as a reasonable investment for one's better professional development, improvement of earnings and increase in intellectual awareness. It can also be stated that for younger ages, whose personality is still subject to change, social parameters exercise a certain influence, which tends to weaken over time (Note 2). On the other hand, we must emphasize the general reluctance towards entrepreneurship; there is statistically significant evidence that, as age advances, "know-how for entrepreneurship" becomes a less appreciated motive for participants to invest in lifelong learning.

\subsection{Obstacles that hinder lifelong learning}

Lack of free time and the cost (Note 3) of lifelong learning are the most important obstacles that hinder the respondents' participation in lifelong learning activities and are related to their personal and professional status. This issue is nothing more than a new aspect of a continuous debate: the rhetoric on offering-easy to combine work and personal life-learning opportunities and the effective exploitation of contemporary financial and time resources (Note 4). On the contrary, professional and family obligations themselves, although they are primary commitments for adults, do not prevent the respondents from taking part in lifelong learning, because such programs are thought to promote multidimensional self-improvement and self-achievement (Table 5). Finally, we must underline the fact that the lack of motives is projected as a serious reason for reduced participation dynamics; this tendency can be attributed to the uncertainty of the effectiveness of the learning concept and content in social and professional settings.

\subsection{Lifelong learning related components}

One of the basic aims of the survey was to explore the attitudes and perceptions of these postgraduate students towards lifelong learning in relation to their deeper motivation, what we called potentiality and dynamics (Note 5). The respondents were asked to express their views with reference to statements, which often appear in lifelong learning rhetoric. Factor analysis was applied to the answers and formed five attitude components that were labelled: "economic development", "social influence", "personality formation", "lifelong learning value" and "lifelong learning potentiality". These components project a different focus on the economic, social and personnal aspects of lifelong learning; the first one clearly presents a functional, therefore more short-term, character focusing on the immediate necessities (mostly benefits) of work related issues; the rest project an aspirational, therefore long-term, character and focus on more indirect (and for this reason rather dubious) outcomes of lifelong learning.

\subsubsection{Economic development}

This component (Table 6.1) basically focuses on the lifelong learning influence on the economic aspects of human society. There is a strong acceptance of the greater value of "learning how to learn", which usually relates to the economic aims of flexibility, adaptability and employability. The respondents consider lifelong learning as a significant, additional qualification to serve someone's professional advancement and increased income; they also express a positive opinion on the implicitly economic role of education in terms of creating useful, that is, productive and effective citizens.

The positive attitude of the respondents decreases when the statements refer to more concrete issues. The respondents critically examine the effectiveness of lifelong learning in confronting the challenges of the future, mainly those of an economic nature, and unemployment, which proves to be a particularly complex and difficult phenomenon to solve. Finally, the compulsory character of lifelong learning is strongly rejected because it interferes with people's free will and, eventually, lifelong learning loses the ability to differentiate individuals. 
In contrast to those employed or exclusively students, who project less optimistic opinions, half of the unemployed individuals strongly agree that lifelong learning helps to confront unemployment and the challenges of the future. Thus, they report their expectations of improving their professional opportunities via the postgraduate program they are currently attending; at the same time, they imply a stronger positive attitude — dynamics — towards future participation in lifelong learning.

\subsubsection{Social influence}

This component (Table 6.2) establishes the idea that lifelong learning affects social activity on an individual and a collective level. It can be observed that the attitude of the participants towards the influence of lifelong learning tends to be more positive when the statements have a more general and abstract character. A significant number of the respondents argue that lifelong learning effectiveness is directly proportionate to the pleasure it creates, while the ability to take advantage of its outcomes depends on human talent and diligence; moreover, they believe that it guides human personality towards broader horizons and tolerance and promotes social justice and equality. These benefits make it a social responsibility.

When the discussion moves to the real function of society as a whole and statements come closer to concrete- and somehow measurable - social situations, the original general enthusiasm about the decisive role of lifelong learning on the social life of individuals weakens. The initial certainty is followed by an implicit uncertainty about its actual potentiality, which is influenced by other determinants, too. The respondents doubt its ability to contribute to the decrease of social problems and reject with certainty that it helps people enhance their social status and gain public recognition, thus having access to a larger proportion of power and social influence.

In most cases, age does not have a statistically significant relation to the variables with two exceptions. Firstly, postgraduate students 22-25 years old totally disagree that people's ability to learn is the same at all ages (Cross, 1981, p. 57), while the rest of the participants indicate a gradually increasing agreement as age increases; after all, their own participation in a postgraduate program confirms their stronger belief. Secondly, age correlates to the belief that lifelong learning participation is people's social responsibility. As age increases, the participants seem to value lifelong learning more and argue with intensity that participating in it is their own social responsibility, therefore a result of free will; on the contrary, younger respondents still continue to attach the orientation and realization of their learning choices to formal education processes.

Besides age, the survey indicated that the respondents' present professional status exercises statistically significant influence on certain variables. First of all, those who are exclusively students totally disagree that people's ability to learn is the same at all ages; but when the statement refers to better dealing with life difficulties with lifelong learning, they show less doubt. Secondly, unemployed participants project statistically significant total disagreement to the idea that offering lifelong learning chances increases social justice and equality, opposed to the total agreement of those employed. On the contrary, they totally accept the fact that individuals have a better quality of life if they participate in lifelong learning. Although they doubt its ability to change general social conditions due to their professional instability and uncertainty, they argue that quality of life on a personal (perhaps emotional) level is improved, because they cherish hopes for better prospects.

\subsubsection{Personality formation}

This component (Table 6.3) tests the role of lifelong learning on the formation of human personality. The strong interest for personal development is apparent in the sample. The majority of the respondents, who obviously constitute a typical paradigm of well-educated persons continuing their studies, rejects the notion that a higher educational level decreases the need for lifelong learning. They also concede that lifelong learning primarily focuses on individuals' skills renewal and attribute to it a supplementary to formal education role.

Most unemployed respondents show statistically significant total agreement with the decrease of the need for lifelong learning in the case of higher educational levels; although they believe that lifelong learning offers help against unemployment, they do not overestimate its potential and accept that it has specific limits to its effectiveness in terms of who receives it and why._

\subsubsection{Lifelong learning value}

This component (Table 6.4) defines the individuals' evaluation of lifelong learning. Most of them certainly acknowledge its value as an additional (and acceptable) qualification in the labor market, when it is offered to all, and as an influential parameter in general; in contrast, the opinions are divergent in the case of esteem that is attributed to lifelong learning nowadays; the respondents believe lifelong learning is given more esteem than it should have, that its actual dynamism is less than believed and that it is overrated as a means to deal with human needs.

\subsubsection{Lifelong learning potentiality}

This component (Table 6.5) refers to the potential ability of lifelong learning to exercise its mission. The great esteem that the respondents attach to lifelong learning leads them to relate its successful outcomes in direct proportion to the 
supply of more resources to it and to younger age. Moreover, they attribute to it a strong influence, which is expressed through the provision of social skills and results in their social and professional evolution. That is why they are strongly in favor of the official certification of lifelong learning. Nevertheless, they do not consider that offering lifelong learning chances would be a motive for them to stay in a job or that it would lead to achieving higher professional positions; these issues seem to be affected by a number of other determinants not necessarily related to learning.

\section{Conclusions}

During the last few decades an explosion in supply and demand for lifelong learning has emerged in both developed and developing economies worldwide. The main aim of this article is to explore the perceptions and attitudes on the role of lifelong learning of students doing postgraduate studies in the University of Macedonia, Greece, taking into consideration personal, social and professional parameters. The article is based on an empirical survey which tested how lifelong learning rhetoric penetrated this group of university-educated persons ideologically and, allegedly, affected their way of thinking, their beliefs, their behavior and, finally, their previous or future choices related to the issue, what we call dynamics and potentiality.

The respondents show great esteem for lifelong learning and it is quite clear that they are conscious of their need to renew or extend their intellectual repertoire, without being deterred by demographic determinants, such as age or gender. The - constantly projected (Floud, Halsey and Martin, 1957; Parsons, 1959; Halsey et al, 1961; Bourdieu, 1971; Checchi, 2006) - finding that persons originating from better-educated families are more likely to pursue studies at a higher level and for longer periods of time is once again confirmed. Moreover, the higher educational level of the participants seems to influence their positive attitude and respect for lifelong learning, as it is already stated in other research studies (Tamkin and Hillage, 1997; Jenkins et al., 2003), reflecting their readiness and stronger expectancy for significant learning, professional and social attainments (Cross, 1981).

The respondents show a remarkably positive attitude towards the influence of lifelong learning on a wide range of human activities of personal, social and employment nature. Nevertheless, although this strong positive attitude becomes less firm when the discussion moves from general issues to more concrete, important and rather urgent ones, such as social problem solving, increasing employability and earnings, confronting unemployment and ameliorating human personality - as Jauhianen (2007) has already concluded for a population with a wider age and educational status variation - they obviously hope to realize their initial expectations by attending the postgraduate program and by strengthening their qualifications. The principle motivation for lifelong learning for this group of Greek students, who are themselves a part of lifelong learning processes through attending a postgraduate progamme, appears to be financial, since they relate their decision to professional content and prospects; so they seem to be more short-term focused on their effort to cope with a complex labor market reality.

They turn to individualism because they primarily acknowledge the profession-oriented advantages of lifelong learning that have a direct impact upon them, and then its broader social reflections. Nevertheless, they seem aware of the fact that the mass participation in higher education in the modern knowledge economy has forced employers to gradually confine their ability to differentiate employees on the basis of knowledge and to increase their evaluation on the basis of socio-cultural factors (Brown, 2003). We must also emphasize their reluctance to proceed to entrepreneurial activities and their preference for safer job choices; so, attracting entrepreneurs as lifelong learning recipients is a new challenge for both lifelong learning planners and researchers.

Younger or unemployed individuals, as opposed to older respondents, seem rather skeptical about lifelong learning effectiveness in certain complex socioeconomic situations, although they are more willing to pay the cost for it than others. Lifelong learning is thought to enhance the dynamics and to offer special potentiality to the individuals that pursue it through the provision of professional and social skills and the formation of a cultivated personality; thus, it promotes not only employability, but also individual well-being (Cross, 1981; Gibbs, 2000, Kember, 2000); nevertheless, they consider it overrated and accept limitations to its effectiveness, keeping in mind that other determinants may influence the interdependent conditions of the modern socioeconomic environment and the aspirations related to learning achievements.

Although postgraduate students are considered to be self-sufficient on learning, because they have already reached an advanced learning cycle, research reveals that they continue to have specific learning needs, which must be satisfied. The search for learning chances also expresses the respondents' dynamics; social networks help to access lifelong learning information, but the Internet and the press are by far the main sources of information. However, when the discussion comes to other groups of people with difficulty in accessing these media, the equality of educational opportunities for all, as well as the maintenance of high self-esteem and positive attitudes towards lifelong learning are called into question (Cross, 1981, COR Model, points A, B, F).

Finally, lack of free time and cost are the main situational barriers to lifelong learning and, strangely enough, go along with a leading dispositional barrier, lack of motivation and interest (Cross, 1981, p. 106-107). This finding once again 
sparks the debate about offering learning opportunities in such a way and with the appropriate content, so as to be easily combined with someone's personal and working life. This opportunity would have a positive effect on their dynamics to acquire knowledge and skills as well as on their potentiality to attend various learning forums throughout their lifetimes. Data referring to the respondents' previous lifelong learning experiences, which were clearly profession oriented, show that in most cases the cost of the program was paid by the employer or was subsidized by the EU and state resources; this funding made the programs accessible and attractive, and, therefore, increased the subjects' potentiality. This finding indicates that removing situational and institutional barriers would significantly reduce dispositional barriers and strengthen positive forces, attitudes and self-perceptions of potential learners.

Generalizations cannot be made on the perceptions and motivations of postgraduate students in other universities, because the results of the survey answer to the exploration of a rather small sample and are confirmed in only one university; nevertheless, there are several indications that certain dimensions are worth to be further explored; the conclusions of this survey have an additional value, because they suggest both the short-term / "functional" and the long-term / "aspirational" focus of the respondents in relation to lifelong learning outcomes. So, it would be very useful to extend similar research on a larger scale, in order to determine whether the variables under consideration actually influence and to what extent can capture various dimensions of adults' motivation to learning and work. If the sample was bigger and the survey expanded to other Greek universities, we would get more significant results and would be able to generalize the findings that reveal the deeper motives which lead postgraduate students to their learning experiences, as well as the obstacles to lifelong learning choices and implementation in Greece. Moreover, a similar research to postgraduate students in other countries would show whether differences in the national labor markets or in the socio-cultural characteristics really influence these perceptions and choices. Basic conclusions would greatly help other researchers, lifelong learning planners and policy makers to consider new strategies and practices.

The increase of those who attend tertiary education is a fact and there are significant indications that these individuals give great credit to lifelong learning. In our opinion it would be very important and useful to extend similar research to a larger sample of university students and graduates, who will always be a pool of interested lifelong learning participants - "clients" - and potential factors for the diffusion of its outcomes. For this reason, in the next few years lifelong learning will be obliged to continue transforming itself, in order to develop a more attractive and inclusive character; thus, it will be likely to contribute decisively to the satisfaction of the needs of individuals, societies, labor markets or even states and supranational formations.

\section{References}

Aspin, D. N. \& Chapman, J.D. (2007). Lifelong learning: Concepts and conceptions. In David N. Aspin (Ed.). Philosophical perspectives on Lifelong learning (pp. 19-38). The Netherlands: Springer.

Bourdieu, P. (1971). Reproduction culturelle et reproduction sociale. Information sur les sciences sociales, X/2, avril, 45-79.

Bourdieu, P. (1986). The forms of capital. In J.G Richardson (Ed.), Handbook of theory and research for the sociology of education (pp. 241-258). New York: Greenwood Press.

Brown, P. (2003). The opportunity trap: education and employment in a global economy. European Educational Research Journal, 2, No 1, 141-179. Retrieved October 5, 2009 from http://www.wwwords.co.uk/pdf/freetoview.asp?j=eerj\&vol=2\&issue=1\&year=2003\&article=a10_Brown_EERJ_2_1

Brown, P. \& Lauder, H. (Eds.) (1992). Education for economic survival: From Fordism to post-Fordism. London: Routledge.

Cedefop. (2003). Lifelong learning: Citizen's views, Cedefop. Luxembourg: Office for Official Publications of the European Communities.

Checchi, D. (2006). The economics of education. Human capital, family background and inequality. Cambridge University Press.

Coffield, F. (1999). Introduction: Lifelong learning as a new form of social control? In F. Coffield (Ed.), Why's the beer always stronger up north? Studies of lifelong learning in Europe. (pp. 1-12). Bristol, UK: Policy Press.

Commission of the European Union. (2001). Report of the Council of Education on the concrete future objectives of education and training systems, 5980/01. Retrieved September 5, 2009 from http://ec.europa.eu/education/policies/2010/doc/rep_fut_obj_en.pdf

Cross, K.P. (1981). Adults as learners. Increasing participation and facilitating learning. San Francisco: Jossey-Bass Publishers.

Edwards, R. (1993). Multi-skilling the flexible workforce in post-compulsory education and training. Journal of Further and Higher Education, 17 (1), 44-51. 
Edwards, R. \& Usher, R. (2001). Lifelong Learning: a postmodern condition of education? Adult Education Quarterly, 51, 273-287.

European Commission. (1993). White Paper. Growth, competitiveness, employment: The challenges and ways forward into the $21^{\text {st }}$ century, COM(93) 700. Luxembourg: European Commission.

European Commission. (1995). White Paper on education and training "Teaching and Learning: towards knowledge society", COM(95) 0590-C4-0597/95. Luxembourg: Office for Official Publications of the European Communities.

European Commission. (2001). Making a European area of lifelong learning a reality, $\operatorname{COM(2001)} 678$ final. Brussels: European Commission.

European Commission. (2002). Education and training 2010: Diverse systems, shared goals. Luxembourg: Office for Official Publications of the European Communities.

European Council. (1997). Main principles for the development of a lifelong learning strategy, EE C 7 of 1-10-1997. (Greek edition)

European Council. (2002). Resolution for lifelong learning (6-27-2002), EE C 163/01 of 7-9-2002.

Field, J. (2005). Social capital and lifelong learning. Bristol, UK: Policy Press.

Field, J. (2006). Lifelong learning and the new educational order $\left(2^{\text {nd }}\right.$ ed.). Stoke on Trent, UK: Trentham Books and USA: Sterling.

Floud, J., Halsey, A.H. \& Martin, F.M. (1957). Social class and educational opportunity. London: Heinemann.

Gibbs, P.T. (2000). Isn't higher education employability ?. Journal of Vocational Education and Training, Vol. 52, No 4, 559-571.

Giddens, A. (1991). Modernity and self identity. Self and society in the late modern age. Cambridge: Polity Press.

Green, A., Wolf, A. \&, Leney, T. (1999). Convergence and divergence in European education and training systems. Institute of Education. London: University of London.

Green, S. B., Salkind, N. J. \& Akey, T. M. (1997). Using SPSS for Windows: Analyzing and understanding data. Upper Saddle River, NJ: Prentice Hall.

Griffin, C. (1998). Lifelong learning and welfare reform. International Journal of Lifelong Education, 18, 431-452.

Hake, B. J. (1998). Lifelong learning and the European Union. A critique from a "risk society" perspective. In J. Holford, P. Jarvis \& C. Griffin (Eds.), International perspectives on lifelong learning (pp. 32-43). London: Kogan Page.

Halsey, A.H. et.al. (1961). Aptitude intellectuelle et éducation. Paris: OECD.

Hantrais, L. (2000). Social policy in the European Union (2 $2^{\text {nd }}$ ed.). London: Palgrave.

Harman, C. \& Brelade, S. (2000). Knowledge management and the role of HR. Securing competitive advantages in the knowledge economy. London: Financial Times-Prentice Hall.

Harvey, L. (2000). New realities: the relationship between higher education and employment. Tertiary Education and Management, 6, 3-17.

Hillage, J. \& Pollard, E. (1998). Employability: developing a framework for policy analysis. London: Department for Education and Employment. Retrieved September $10, \quad 2009$ from http://www.dcsf.gov.uk/research/data/uploadfiles/RB85.pdf

Hughes, C. \& Tight, M. (1995). The myth of the learning society. British Journal of Educational Studies, XXXXIII (3), 290-304.

Illeris, K. (2003). Adult education as experienced by the learners. International Journal of Lifelong Education, 22(1), 13-23. Retrieved $\quad$ December $\quad 10, \quad 2009$ from http://www.ingentaconnect.com/content/routledg/tled/2003/00000022/00000001/art00003

Jacquemin, A. \& Pench, L. R. (Eds.) (1997). Europe competing in the global economy, Reports of the competitiveness Advisory Group. Cheltenham UK-Lyme US: Edward Elgar Publishing.

Jarvis P. (1998). Paradoxes of the learning society. In J. Holford, P. Jarvis \& C. Griffin (Eds.). International perspectives on Lifelong Learning (pp. 59-68). London: Kogan Page.

Jauhiainen, A. (2007). Ageing peoples' faith in education and learning society. Paper presented at the International Sociological Association Conference «New directions in Sociology of Education in/for the $21^{\text {st }}$ century», Nicosia, Cyprus (May 25-27, 2007). Not included in the e-proceedings. 
Jenkins, A., Vignoles, A., Wolf, A., \& Galindo-Rueda, F. (2003). The determinants and labour market effects of lifelong learning. Applied Economics, 35, 1711-1721.

Kember, D. (2000). Misconceptions about learning approaches, motivation and study practices of Asian students. Higher Education, 40, 99-121. Retrieved December 8, 2009 from http://www.springerlink.com/content/q97v8075385179x0/fulltext.pdf

Kleinman, M. (2002). A European welfare state? European Union social policy in context. Houndmills, Basingstoke, Hants, UK: Palgrave Macmillan.

Mihail, D. M. \& Elefterie, K. A. (2006). Perceived effects of an MBA degree on employability and career advancement. The case of Greece. Career Development International, 11(4), 352-361.

Organization for Economic Cooperation and Development. (2001). The Well-being of nations: the role of human and social capital. Paris: OECD.

Organization for Economic Cooperation and Development. (2007). Qualifications systems: Bridges to lifelong learning. Paris: OECD.

Parsons, T. (1959). The school-class as a social system: some of its functions in American society. Harvard Educational Review, 29(4), 297-318.

Rubenson, K. (2000). Adults' Readiness to Learn: Questioning Lifelong Learning for All. Paper presented at the Annual Conference of the Australian Association for Research in Education and the University of Sydney, Sydney (December 5, 2000). On-line proceedings published January 2001 by the Association of Active Educational Researchers (AARE). Retrieved December 14, 2009 from https://www.aare.edu.au/00pap/rub00473.htm

Schuetze, H.G. \& Slowey, M. (2002). Participation and exclusion: a comparative analysis of non-traditional students and lifelong learners in higher education. Higher Education, 44, 309-327. Retrieved December 14, 2009 from http://www.springerlink.com/content/u162346j8k6u5217/fulltext.pdf

Tabachnick, B. G. \& Fidell, L. S. (2001). Understanding multivariate statistics. Boston: Allyn \& Bacon.

Tamkin, P. \& Hillage, J. (1997). Individual commitment to learning: motivation and rewards. Research Report RR11, Department for Education and Employment (DfEE). United Kingdom.

Tight, M. (1998). Education, education, education! The vision of lifelong learning in the Kennedy, Dearing and Fryer reports. Oxford Review of Education, 24(4), 473-485.

Tissot, P. (2004). Terminology of vocational training policy. A multilingual glossary for an enlarged Europe, Cedefop. Luxembourg: Office for Official Publications of the European Communities.

Tsekouras, J., Stamboulis, M. \& Litsardakis, M. (2003). The financing of vocational education and training in Greece. Financing portrait, Cedefop, Panorama series 78. Luxembourg: Office for Official Publications of the European Communities.

UNESCO. (2008). Medium-Term Strategy 2008-2013, 34 C/4. Paris: UNESCO.

Wain, K. (2000). The learning society: postmodern politics. International Journal of Lifelong Education, 19 (I), 36-53.

\section{Notes}

Note 1. The Chain-of-Response (COR) Model includes the following points: (A) self-evaluation; (B) attitudes about education; (C) importance of goals and expectation that participation will meet goals; (D) life transitions; (E) opportunities and barriers; (F) information; (G) participation.

Note 2. Also see Cross, 1981, p. 235-240.

Note 3. In many cases lifelong learning participation may be financed by a special fund (Fund for Employment and Vocational Training, $\Lambda$.A.E.K. in Greek), which is funded by the contribution of employers and employees $(0.45 \%$ on the salary). (Tsekouras, Stamboulis and Litsardakis 2003, p. 21-22).

Note 4. i.e. Facilitating employees with on-the-job learning or educational full-pay leave, time management training, child care provision, etc.

Note 5. Also see Cross, 1981, p. 124-127, COR Model, point B and its correlations. 
Table 1. Distribution of the sample by postgraduate program

\begin{tabular}{|c|c|c|c|c|}
\hline Postgraduate Studies Department & Frequency & Total (\%) & Men (\%) & Women (\%) \\
\hline European Studies and Diplomacy $^{\mathrm{a}}$ & 6 & 5.6 & 6.7 & 4.8 \\
\hline Strategic Studies and International Politics ${ }^{\mathrm{a}}$ & 1 & 0.9 & 2.2 & 0.0 \\
\hline European Youth Studies $^{\mathrm{a}}$ & 19 & 17.6 & 13.3 & 20.6 \\
\hline MBA executive & 24 & 22.2 & 28.9 & 17.5 \\
\hline MBA for young graduates & 32 & 29.6 & 24.4 & 33.3 \\
\hline Total Quality Public Management & 26 & 24.1 & 24.4 & 23.8 \\
\hline Total & 108 & 100.0 & 100.0 & 100.0 \\
\hline
\end{tabular}

Table 2. Present professional status

\begin{tabular}{|c|c|c|c|c|}
\hline (1) Present professional status & Frequency & Total (\%) & Men (\%) & Women (\%) \\
\hline Employed & 86 & 79.6 & 82.2 & 77.8 \\
\hline Unemployed & 4 & 3.7 & 4.4 & 3.2 \\
\hline Student (exclusively) & 18 & 16.7 & 13.3 & 19.0 \\
\hline Total & 108 & 100.0 & 100.0 & 100.0 \\
\hline \multicolumn{5}{|l|}{ (2) Type of employment } \\
\hline Self-employed with personnel & 2 & 2.4 & 5.4 & 0.0 \\
\hline Self-employed without personnel & 4 & 4.8 & 2.7 & 6.4 \\
\hline Salaried (monthly or daily) & 76 & 90.5 & 89.2 & 91.5 \\
\hline Aid in the family business & 2 & 2.4 & 2.7 & 2.1 \\
\hline Total & 84 & 100.0 & 100.0 & 100.0 \\
\hline \multicolumn{5}{|c|}{ (3) Professional position of responsibility } \\
\hline Director / Assistant Director & 5 & 23.8 & 30.0 & 18.2 \\
\hline Departmental Manager & 12 & 57.1 & 70.0 & 45.5 \\
\hline Supervisor & 4 & 19.0 & 0.0 & 36.4 \\
\hline Total & 21 & 100.0 & 100.0 & 100.0 \\
\hline
\end{tabular}

Table 3. Information sources on lifelong learning

\begin{tabular}{|l|r|r|r|}
\hline \multicolumn{1}{|c|}{ Information Sources } & \multicolumn{1}{c|}{$\begin{array}{c}\text { Percentage } \\
\text { response (\%) }\end{array}$} & Men (\%) & Women (\%) \\
\hline Advertisements in various magazines & 37.4 & 40.0 & 35.5 \\
\hline Electronic mass media (TV, radio) & 30.8 & 28.9 & 32.3 \\
\hline Internet & 85.0 & 86.7 & 83.9 \\
\hline Friendly environment & 34.6 & 17.8 & 46.8 \\
\hline Advertisement brochures & 20.6 & 22.2 & 19.4 \\
\hline Other trainees & 29.0 & 20.0 & 35.5 \\
\hline Personal search in training institutions & 9.3 & 2.2 & 14.5 \\
\hline
\end{tabular}


Table 4. Reason for postgraduate program participation / Reason for lifelong learning participation

\begin{tabular}{|c|c|c|c|}
\hline \multicolumn{4}{|c|}{ Friedman Test for the comparison of the items } \\
\hline $\begin{array}{l}\text { Reason for postgraduate program } \\
\text { participation }\end{array}$ & $\begin{array}{l}\text { Mean } \\
\text { Rank }\end{array}$ & Reason for lifelong learning participation & $\begin{array}{l}\text { Mean } \\
\text { Rank }\end{array}$ \\
\hline Personal interest & 9.83 & Personal interest & 8.72 \\
\hline Better professional development & 9.18 & Relation to my job & 8.35 \\
\hline Securing special knowledge & 8.33 & Better professional development in my job & 8.09 \\
\hline Good reputation of the program & 6.83 & Offer modern and applied knowledge & 7.69 \\
\hline Increase chances of finding a job & 6.77 & Relation to my studies & 7.35 \\
\hline High demand in labor market & 6.74 & Better payment development in my job & 6.89 \\
\hline Securing high financial income & 6.52 & Acquire social skills & 6.39 \\
\hline $\begin{array}{l}\text { Connection of the program to the labor } \\
\text { market }\end{array}$ & 6.03 & Potential finding of a job with better conditions & 5.98 \\
\hline High social acceptance & 5.86 & Know-how for entrepreneurship & 5.82 \\
\hline Accessible tuition fees & 4.87 & $\begin{array}{l}\text { "Guarantee" to keep my job position by the } \\
\text { company that employs me }\end{array}$ & 4.88 \\
\hline Having free time & 3.93 & Participate in social activities & 4.51 \\
\hline $\begin{array}{l}\text { The company that employs me pays the } \\
\text { tuition fees }\end{array}$ & 3.11 & Taking advantage of free time & 3.32 \\
\hline
\end{tabular}

Table 5. Obstacles for lifelong learning participation

\begin{tabular}{|l|r|}
\hline \multicolumn{1}{|c|}{ Obstacles that hinder LLL } & \multicolumn{1}{c|}{ Total (\%) } \\
\hline Lack of free time & 41.7 \\
\hline Professional obligations & 11.1 \\
\hline Family obligations & 9.3 \\
\hline Cost of participation & 27.8 \\
\hline Lack of information & 10.2 \\
\hline Improper educators, content or quality & 9.3 \\
\hline Lack of motives & 24.1 \\
\hline
\end{tabular}


Table 6. Attitude components

\begin{tabular}{|c|c|}
\hline \multicolumn{2}{|l|}{ Friedman Test for the comparison of the items } \\
\hline Component 1. Economic Development & Mean Rank \\
\hline Lifelong learning must have a compulsory character & 5.16 \\
\hline Lifelong learning is an effective way to confront unemployment & 3.71 \\
\hline Participation in lifelong learning is the only way to confront the challenges of the future & 3.64 \\
\hline The more educated a person is, the more useful he is to society & 3.00 \\
\hline People with greater participation in lifelong learning activities earn more than those with less & 2.76 \\
\hline Learning how to learn is more important than simply acquiring knowledge and skills & 2.72 \\
\hline Component 2. Social influence & Mean Rank \\
\hline People's ability to learn is the same during all ages & 9.54 \\
\hline People who participate in lifelong learning activities achieve a higher social status & 8.63 \\
\hline $\begin{array}{l}\text { Greater participation of individuals in lifelong learning will contribute to the decrease of many social } \\
\text { problems }\end{array}$ & 6.96 \\
\hline $\begin{array}{l}\text { Lifelong learning helps people confront adverse circumstances in life more than knowledge acquired in } \\
\text { formal education }\end{array}$ & 6.83 \\
\hline People who participate in lifelong learning activities have a better quality of life & 6.82 \\
\hline People can deal with the difficulties of life with lifelong learning & 6.54 \\
\hline Participation in lifelong learning for self-improvement is every person's social responsibility & 4.88 \\
\hline Offering more lifelong learning chances increases social justice and equality & 4.78 \\
\hline $\begin{array}{l}\text { Taking advantage of the knowledge and skills acquired through lifelong learning depends on a person's talent } \\
\text { and diligence }\end{array}$ & 4.31 \\
\hline Lifelong learning contributes to the formation of individuals with broader horizons and tolerance & 3.91 \\
\hline Lifelong learning is more effective when it pleases the individual & 2.79 \\
\hline Component 3. Personality Formation & Mean Rank \\
\hline The higher educational level someone has, the less need for lifelong learning he has & 2.22 \\
\hline Lifelong learning must aim at someone's self-improvement and not collectivism & 1.98 \\
\hline Formal education renews knowledge, while lifelong learning only a person's skills & 1.80 \\
\hline Component 4. Lifelong learning value & Mean Rank \\
\hline Offering lifelong learning activities to all decreases its value as an additional qualification & 2.21 \\
\hline Lifelong learning is useful only when it exclusively refers to work & 2.12 \\
\hline Lifelong learning is overrated today & 1.67 \\
\hline Component 5. Lifelong learning potentiality & Mean Rank \\
\hline $\begin{array}{l}\text { Persons who participate more in lifelong learning activities achieve higher professional positions than those } \\
\text { who don't }\end{array}$ & 4.44 \\
\hline Offering lifelong learning chances is a motive to stay in a job & 3.68 \\
\hline Participation in lifelong learning programs must lead to an official studies certificate & 3.64 \\
\hline $\begin{array}{l}\text { Acquiring social skills helps the social and professional evolution of individuals more than knowledge } \\
\text { acquired through formal education }\end{array}$ & 3.64 \\
\hline The younger a person is, the easier he can correspond to lifelong learning activities & 3.34 \\
\hline If more resources were given to lifelong learning, it would be more successful & 2.26 \\
\hline
\end{tabular}

